BMJ Open

Diabetes

Research

\& Care

\title{
Clinical decision support to improve management of diabetes and dysglycemia in the hospital: a path to optimizing practice and outcomes
}

\author{
Ariana Pichardo-Lowden (D) , ', Guillermo Umpierrez (D) , ${ }^{2}$ Erik B Lehman, ${ }^{3}$ \\ Matthew D Bolton, ${ }^{4}$ Christopher J DeFlitch, ${ }^{5}$ Vernon M Chinchilli, ${ }^{3}$ Paul M Haidet ${ }^{6}$
}

To cite: Pichardo-Lowden A, Umpierrez G, Lehman EB, et al. Clinical decision support to improve management of diabetes and dysglycemia in the hospital: a path to optimizing practice and outcomes. BMJ Open Diab Res Care 2021;9:e001557. doi:10.1136/ bmjdrc-2020-001557

Received 13 May 2020 Revised 8 November 2020 Accepted 17 November 2020

Check for updates

(c) Author(s) (or their employer(s)) 2021. Re-use permitted under CC BY-NC. No commercial re-use. See rights and permissions. Published by BMJ.

For numbered affiliations see end of article.

Correspondence to Dr Ariana Pichardo-Lowden; apichardolowden@ pennstatehealth.psu.edu

\section{ABSTRACT}

Introduction Innovative approaches are needed to design robust clinical decision support (CDS) to optimize hospital glycemic management. We piloted an electronic medical record (EMR), evidence-based algorithmic CDS tool in an academic center to alert clinicians in real time about gaps in care related to inpatient glucose control and insulin utilization, and to provide management recommendations. Research design and methods The tool was designed to identify clinical situations in need for action: (1) severe or recurrent hyperglycemia in patients with diabetes: blood glucose $(B G) \geq 13.88 \mathrm{mmol} / \mathrm{L}(250 \mathrm{mg} / \mathrm{dL})$ at least once or $B G \geq 10.0 \mathrm{mmol} / \mathrm{L}(180 \mathrm{mg} / \mathrm{dL})$ at least twice, respectively; (2) recurrent hyperglycemia in patients with stress hyperglycemia: $B G \geq 10.0 \mathrm{mmol} / \mathrm{L}(180 \mathrm{mg} / \mathrm{dL})$ at least twice; (3) impending or established hypoglycemia: BG 3.9$4.4 \mathrm{mmol} / \mathrm{L}(70-80 \mathrm{mg} / \mathrm{dL})$ or $\leq 3.9 \mathrm{mmol} / \mathrm{L}(70 \mathrm{mg} / \mathrm{dL})$; and (4) inappropriate sliding scale insulin (SSI) monotherapy in recurrent hyperglycemia, or anytime in patients with type 1 diabetes. The EMR CDS was active (ON) for 6 months for all adult hospital patients and inactive (OFF) for 6 months. We prospectively identified and compared gaps in care between $\mathrm{ON}$ and OFF periods.

Results When active, the hospital CDS tool significantly reduced events of recurrent hyperglycemia in patients with type 1 and type 2 diabetes (3342 vs $3701,0 R=0.88$, $\mathrm{p}=0.050)$ and in patients with stress hyperglycemia (288 vs $506,0 R=0.60, p<0.001$ ). Hypoglycemia or impending hypoglycemia ( 1548 vs $1349,0 R=1.15, p=0.050$ ) were unrelated to the CDS tool on subsequent analysis. Inappropriate use of SSI monotherapy in type 1 diabetes ( 10 vs $22,0 R=0.36, p=0.073$ ), inappropriate use of SSI monotherapy in type 2 diabetes ( 2519 vs $2748,0 R=0.97$, $p=0.632$ ), and in stress hyperglycemia subjects (1617 vs 1488, $\mathrm{OR}=1.30, \mathrm{p}<0.001$ ) were recognized.

Conclusion EMR CDS was successful in reducing hyperglycemic events among hospitalized patients with dysglycemia and diabetes, and inappropriate insulin use in patients with type 1 diabetes.

\section{INTRODUCTION}

The year 2020 is the proposed target for the Institute of Medicine when most clinical decisions will be supported by timely, up-todate, and accurate information reflecting

\section{Significance of this study}

What is already known about this subject?

- The positive impact of clinical decision support on healthcare processes, implementation of guidelines, and clinical benefits is expanding.

What are the new findings?

- In this study, we present the development, testing and benefits of an innovative real-time clinical decision support tool synchronized to clinicians' workflow that recognizes gaps in glycemic control and management, and provides evidence-based recommendations.

- This tool's novel design capitalizes on iteratively identifying common data elements in the electronic health records for glucose control and insulin practices in different hospital populations departing from safe or recommended clinical guidelines.

How might these results change the focus of research or clinical practice?

- This work provides a framework for advancing health information technology through clinical decision support applying timely, up-to-date, efficient and evidenced-based recommendations in real-time individualized to patients, while fostering better outcomes within learning healthcare systems.

- This is a novel real-time clinical decision support tool that identifies dysglycemia and inappropriate insulin use in the hospital, and notifies clinicians through the EMR about these gaps in care and presents recommendations for management.

> It offers automated and iterative identification of scenarios departing from glycemic goals or optimal diabetes practice.

- It suggests how clinical decision support may drive practice performance and reduces undesirable clinical events.

- It outlines a framework for optimization of hospital glycemic management through clinical decision support with great potential for improving clinical and economic outcomes.

best evidence while fostering learning healthcare systems and offering the most appropriate care to each patient. ${ }^{1}$ Well-developed 
inpatient diabetes care guidelines and careful transitions of care aligned with standards of practice recommendations are needed. This notion gains additional relevance considering that hyperglycemia and hypoglycemia events in hospitalized individuals are associated with unfavorable outcomes including greater morbidity and mortality risk. ${ }^{2-4}$ Adequate inpatient glycemic control is encouraged by the evidence of improved clinical outcomes and satisfactory utilization of hospital resources such as reductions in hospital stay and readmission rates. ${ }^{2-4}$ Standards for inpatient diabetes care are well defined, and management programs are expected to occur within health systems that support best practices and promote optimal clinical performance. The goal is to provide the highest quality and the safest care across hospital populations while considering an individualized approach to patient care based on best evidence using approaches that promote learning health systems. ${ }^{1}$

Many challenges in the practice of diabetes care in the hospital limit clinicians' performance. There is significant complexity in data gathering and processing in the electronic health records for the evaluation of diabetes, glucose control, and insulin treatment in acutely ill patients. ${ }^{5}$ Furthermore, many practice barriers exist among multiple providers from different disciplines and levels of training. These obstacles seem to prevail despite advocacy for improvement of clinical practices and health systems. ${ }^{6-17}$ These are recognized deficiencies in practice performance and healthcare delivery in the inpatient setting and transitions of care. ${ }^{513-15} 18$ Regardless of these barriers, inpatient diabetes care warrants providers' optimal performance to meet expected care goals, and hospitals' teams to stand accountable for the provision of the safest and most effective care. There is a need to identify and test innovative ideas to improve the quality of diabetes care in hospitals.

The use of computable knowledge related to personspecific health information intelligently filtered and processed and presented in the right context to facilitate clinical decisions to enhance health and healthcare represents clinical decision support (CDS) ${ }^{19}$ Evidence of effective development of CDS on healthcare processes, adoption of guidelines, clinical and economic outcomes is growing. ${ }^{20}$ In diabetes, evidence of the benefits of CDS mostly derives from ambulatory settings. ${ }^{21}{ }^{22}$ Hospital benefits for diabetes have been mostly shown in studies using computerized physician order entry systems, connectivity technology-based intervention of point of care blood glucose transfer for analysis, case finding of in-need patients, and integrated algorithms for insulin dosing and adjustments. ${ }^{23-30}$ Most studies have been observational and descriptive. Reported benefits include lower mean blood glucose, less use of sliding scale insulin (SSI), and greater use of basal-bolus insulin regimen. ${ }^{23}$ Prospective randomized and non-randomized studies demonstrated an increased proportion of blood glucose levels within range and/or reduced hypoglycemia. ${ }^{24}$ Programs using diabetes management teams count on a beneficial resource; however, this service is not available to all hospitals. Given the high prevalence of dysglycemia in hospitals, there is a need for finding more inclusive innovative solutions to address disparities in hospital resources. The Office of the National Coordinator calls for advancing Health Information Technology (HIT) capabilities on CDS while promoting quality measures and driving innovation to apply best evidence and choices leading to better outcomes. ${ }^{31}$

This work presents the development of a real time CDS tool for management of patients with diabetes and dysglycemia in the hospital. We capitalize on a design that circumvents barriers that jeopardize adequate management and reduces the burden of data gathering and processing. We hypothesized that this diabetes CDS tool will reduce scenarios of recurrent and severe hyperglycemia and hypoglycemia and inappropriate utilization of insulin therapy through the provision of recommendations in the context of practice. We report the impact of this tool on reducing prevalent gaps in glycemic care in the hospital and present how our findings support improvements in practice performance and quality of care.

\section{RESEARCH DESIGN AND METHODS}

\section{CDS tool development and utilization}

The design of this CDS tool considered hospital diabetes management departing from best practice or from desirable outcomes, which we coined 'gaps in care'. The tool notified providers in real time through the electronic medical record. These 'gaps in care' scenarios included uncontrolled glycemia and suboptimal insulin treatment choices, encompassing two important domains of hospital management: glucose control and insulin therapy. Diabetes clinical practice guidelines ${ }^{2-4}$ and expert opinion (APL and GU) informed the set of criteria for the definition of 'gap in care events'. Additionally, practice guidelines provided reference to evidence-based recommendations for glucose targets and insulin management approaches. ${ }^{2-4}$ In the domain of glucose control requiring treatment adjustment, abnormal blood glucose was categorized as severe hyperglycemia (blood glucose $\geq 13.88 \mathrm{mmol} / \mathrm{L}(250 \mathrm{mg} / \mathrm{dL}$ at least once) or recurrent hyperglycemia in subjects with diabetes or recurrent hyperglycemia in stress hyperglycemia (blood glucose $\geq 10.0 \mathrm{mmol} / \mathrm{L}(180 \mathrm{mg} / \mathrm{dL})$ at least twice, 3 hours apart $)$, and impending hypoglycemia or established hypoglycemia (any blood glucose 3.9 to $4.44 \mathrm{mmol} / \mathrm{L}(70-80 \mathrm{mg}$ / $\mathrm{dL})$ or $\leq 3.9 \mathrm{mmol} / \mathrm{L}(70 \mathrm{mg} / \mathrm{dL})$, respectively). In the domain of insulin therapy, inappropriate insulin use was defined as use of SSI monotherapy (no scheduled basal or prandial insulin in active orders) in subjects with recurrent hyperglycemia (blood glucose $\geq 10.0 \mathrm{mmol} / \mathrm{L}$ $(180 \mathrm{mg} / \mathrm{dL})$ at least three times, 3 hours apart), whether with stress hyperglycemia in those without a diabetes diagnosis, or patients with type 2 diabetes, or anytime in patients with type 1 diabetes. The identification of 
type 1 and type 2 diabetes was based on International Statistical Classification of Diseases and Related Health Problems (ICD-10) codes and Systematized Nomenclature of Medicine Clinical Terms (SnoMed CT) captured as a discrete data elements. Stress hyperglycemia was recognized by the absence of an ICD-10 or SnoMed CT codes for diabetes. The tool was designed considering characteristics emulating clinical practice, hospital workflow and decision making. It considered time needed for providers to execute recommendations and observe change effects. The program assessed the rules to identify gaps in care 24 hours from previous. The appearance of new alerts was programmed between 12-48 hour periods depending on the urgency of the scenario. Gap in care recognition and recommendations messages could be evoked any time from admission if criteria were present for scenarios requiring more immediate attention, such as hypoglycemia or impending hypoglycemia, and type 1 diabetes patients only receiving SSI monotherapy. Messages related to hyperglycemia were evoked when repeated elevated glucose values were present, which for new admissions was usually several hours from admission. Repeated messages were restricted to 48 hours (hyperglycemia), 24hours (hypoglycemia and inappropriate insulin in type 2 diabetes and stress hyperglycemia) and 12 (inappropriate insulin in type 1 diabetes) from the previous. When undesirable criteria were no longer present, gap in care event messages were no longer evoked. Our tool design excluded alerts for hyperglycemia if the endocrinology service was managing. This intended to avoid simultaneous recommendations to admitting teams deriving from the tool and endocrine service. This also intended to reduce result bias since better management of hyperglycemia is anticipated for patients under care of endocrinology services.

The design of the CDS tool was based on a conceptual model that recreated the common clinical scenarios described representing gaps in care in hospital glucose management. A team composed by clinicians, nurses, data management specialists, information technology developers, and biostatisticians convened regularly to iteratively recreate these scenarios and to program rules enabling tool functionality... Descriptors and identifying factors of gaps in care were aggregated to develop algorithmic workflows. These workflows were used to program data queries of nested electronic health records data elements to identify cases in real time. Upon identification of cases, individualized messages appeared in the record of patients for the admitting providers or members of the primary team to consider for management. The concepts included in the model are: (A) descriptors of gap in care scenarios, (B) execution factors and (C) clinical recommendations. Descriptors of gap in care scenarios included patients' demographics such as age $\geq 18$ years, factors departing from standard of care recommendations observed in practice guidelines, presence or absence of diabetes diagnosis, and hospital setting where patients were admitted. Only the inpatient setting was considered in the model for hyperglycemia or for inappropriate insulin use as SSI monotherapy. Inpatient, same-day admission, observation and emergency department settings were considered in the model for hypoglycemia given the immediacy of attention required regardless of hospital location. The hospital's hypoglycemia management protocol was not dependent on this tool. Execution factors included workflow logistics such as timing specifications for search of abnormal glucose criteria or insulin treatment, and provider attribution for messages. Clinical recommendations offered by the tool's messages encompased practice guidelines, expert clinical acumen, and hospital resources. The content of evoked messages corresponding to gaps in care was in alignment with recommended clinical practice guidelines. Automated messages were uniquely composed to denote the individualized problem detected; a statement emphasizing potential outcomes to incentivize thinking and action; patients' specific glucose data trends; and management recommendations supported by scientific evidence. The management recommendations outlined in the message included glycemic targets, insulin initiation and titration recommendations, and an access link to literature for more comprehensive information as needed. Figures 1-3 show three representative examples among several alert notifications and recommendations offered by the tool. These correspond to events of hypoglycemia, stress hyperglycemia, and insulin sliding scale monotherapy in a patient with type 2 diabetes with recurrent hyperglycemia. Our design employed an expert peer review process to ratify recommendations corresponding to gaps in care scenarios. This included iterative feedback on content, language and clarity of messages that substantiated applicability and integration of the program.

In order to prevent inadequate repetition of gaps in care, in the design of this tool we considered time required for decision making and to observe effects of management changes applicable to routine clinical practice. These messages corresponding to gaps in care were presented in the EMR as synchronous alerts when providers were in the record of corresponding patients in real time. This design presented the information in a way that intended to facilitate learning about the gap in care scenarios and their management while situated in the context of clinical practice.

\section{Process of validation and implementation in clinical practice}

Findings of a previous qualitative needs assessment study using semistructured interviews of clinicians denoted their interest in having support for glucose management in the hospital using information technology. The perspectives of inpatient providers ratified a need of clinicians, and endorsed the development of the CDS tool and its implementation program. ${ }^{32}$ Prior to the integration of the tool in the clinical EMR environment, we conducted an exhaustive authentication process. This consisted in direct chart audits for accuracy verification of algorithmic workflows enabling cases 
HYPOGLYCEMIA: INSULIN ADJUSTMENT NEEDED TO PREVENT FUTURE EVENTS!

Recurrent hypoglycemia is associated with increased morbidity, mortality risk and length of hospital stay

$88 \mathrm{mg} / \mathrm{dL} @ 10 / 22 / 20$ 10:59:00

* $51 \mathrm{mg} / \mathrm{dL} @$ 10/22/20 09:39:00 LOW

* $65 \mathrm{mg} / \mathrm{dL} @$ 10/22/20 09:00:00 LOW

$80 \mathrm{mg} / \mathrm{dL} @ 10 / 22 / 2008: 20: 00$

* 26 mg/dL @ 10/22/20 07:40:00 LOW

$154 \mathrm{mg} / \mathrm{dL} @ 10 / 21 / 20$ 21:32:00

$118 \mathrm{mg} / \mathrm{dL} @ 10 / 21 / 2017: 24: 00$

$71 \mathrm{mg} / \mathrm{dL} @ 10 / 21 / 2014: 14: 00$

Values at Risk:

At risk for hypoglycemia $=100-81 \mathrm{mg} / \mathrm{dl}$

Near hypoglycemia $\leq 80-71 \mathrm{mg} / \mathrm{dl}$

Hypoglycemia $=70-41 \mathrm{mg} / \mathrm{dl}$ (夰oderate) $\leq 40 \mathrm{mg} / \mathrm{dl}$ ( (severe)

Insulin Treatment Recommendations:

Look for patterns of hypoglycemia or hyperglycemia. If patient is receiving insulin, consider the following adjustments depending

when the low glucose event occurred.

-FASTING LOW= anytime if NPO or after overnight fasting - reduce basal insulin

(detemir, degludec, glargine, or NPH) dose by at least $20 \%$.

-LOW BEFORE MEALS - reduce prandial insulin dose (lispro, aspart, or regular)

by at least $20 \%$ for the meal prior to the low event (example - too much insulin for

lunch can cause pre-dinner low glucose).

-LOW ON INSULIN DRIP - follow the recommendations per drip protocol.

Insulin sliding scale choice depends on total daily insulin dose (TDD). Consider these scale doses: If TDD $<30$ units, use Ultra-Low (1 unit for every $50 \mathrm{mg} / \mathrm{dl}>150$ ); 31-60 units, use Low ( 2 unit for every $50 \mathrm{mg} / \mathrm{dl}>150$ ); 61-100 units, use Moderate ( 3 unit for every 50 $\mathrm{mg} / \mathrm{dl}>150$ ); $>101$ units, use High (5 unit for every $50 \mathrm{mg} / \mathrm{dl}>150$ )

Glucose Targets in the Hospital:

*Non-pregnant:

Fasting, 110 to $140 \mathrm{mg} / \mathrm{dl}$

Random or before meals, $<180 \mathrm{mg} / \mathrm{dl}$

*Pregnant:

Anytime, 72 to $126 \mathrm{mg} / \mathrm{dl}$

Targets should be individualized in the elderly and patients at risk for hypoglycemia.

Alerts may appear in the electronic records of patients with and without diabetes. The absence of alerts in other patients should NOT be interpreted as no action required for glucose management. This is a clinical tool in progress.

Figure 1 Example of alert notification and management recommendations for hypoglycemia.

detection. This assessment of precision reaffirmed the expected reliability of the tool. We conducted random audits during each $\mathrm{ON}$ and OFF periods of the study demonstrating complete alignment between design and product. Prior to the introduction of this CDS tool to hospital clinical practice, the program was endorsed by the hospital's chief medical office. In order to inform hospital providers of this new practice resources, we carried a communication agenda of in-person informational sessions to inpatient clinical services and email announcements by the study lead (APL).

\section{Study design}

The study population included subjects $\geq 18$ years of age admitted to the emergency department, observation units, inpatient units or same-day admission with or without diabetes among whom gaps in care could have been identified. We piloted the tool across all adult hospital services and in all intensive and non-intensive inpatients units and the emergency department at an academic quaternary care medical center during the period from March 2018 to February 2019. This prospective intervention encompassed four alternating phases lasting 3 months each. There were two active phases (ON period) representing 6 months of study time from March to May and from September to November 2018 and two inactive phases (OFF period) representing 6 months of control period from June to August 2018, and from December 2018 to February 2019. To avoid crossover bias, we excluded from the analysis the gap in care events that were identified for patients crossing from the ON to OFF and from the OFF to ON periods. During the ON period of the study, the gaps in care scenarios recognized in the records of patients evoked alerts messages and disease management recommendations for clinicians in real time for their consideration. During the OFF period, the tool only recorded gaps in care events, but alerts were inactive for viewing. Data related to the study population (based on all adults 
*304 mg/dL @ 10/27/20 05:51:00 HIGH

* $229 \mathrm{mg} / \mathrm{dL} @ 10 / 26 / 20$ 23:33:00 HIGH

* $258 \mathrm{mg} / \mathrm{dL} @ 10 / 26 / 20$ 17:37:00 HIGH

*237 mg/dL @ 10/26/20 13:10:00 HIGH

* $212 \mathrm{mg} / \mathrm{dL} @ 10 / 26 / 20$ 08:17:00 HIGH

$179 \mathrm{mg} / \mathrm{dL} @ 10 / 25 / 20$ 21:11:00

$139 \mathrm{mg} / \mathrm{dL} @ 10 / 25 / 2016: 52: 00$

178 mg/dL@10/25/20 11:24:00

Hyperglycemia in patients without diabetes results in worse outcomes than for patients with diabetes.

Glucose targets in the hospital:

*Non-pregnant:

Fasting 110 to $140 \mathrm{mg} / \mathrm{dl}$

Random or before meals $<180 \mathrm{mg} / \mathrm{dl}$

*Pregnant:

Anytime 72 to $126 \mathrm{mg} / \mathrm{dl}$

Targets should be individualized in the elderly and patients at risk for hypoglycemia.

\section{Insulin treatment recommendation:}

-If not on insulin: consider initiating insulin (basal if fasting hyperglycemia and

prandial if hyperglycemia when eating).

-If already on insulin:

Fasting hyperglycemia: Increase basal insulin (detemir, degludec, glargine or NPH).

Hyperglycemia before meals or randomly: Increase prandial insulin (lispro, aspart or regular) with the meal before the high glucose level(s) occurred.

Approximately $10 \%$ increment of doses at a time is appropriate in most cases.

-If on an insulin drip: Adjust per drip protocol.

Basal insulin dosing to consider:

-Calculate total daily basal insulin to be 0.1 to 0.3 units $x \mathrm{~kg}$ per day. For example, if considering 0.2 units $\times \mathrm{kg}$, a $100 \mathrm{~kg}$ person may require 20 units of basal insulin per day.

Prandial insulin dosing to consider (if eating):

-Calculate total prandial insulin to be 0.1 to 0.3 units $\times \mathrm{kg}$ per day divided in 3 doses. For example, a $100 \mathrm{~kg}$ person may require 20 units of prandial insulin per day in addition to basal insulin. This is equivalent to 6 or 7 units of insulin with each meal.

-Request hemoglobin A1c to assess for possible diabetes.

Alerts mav appear in the electronic records of patients with and without diabetes. The absence of alerts in other patients should NOT be interpreted as no action required for glucose management. This is a clinical tool in progress.

Figure 2 Example of alert notification and management recommendations for stress hyperglycemia. NPH, Neutral Protamine Hagedorn; NPO, nil per os or nothing by mouth.

hospital admissions) and demographics of the study sample and control (pertinent subjects in whom gaps in care events were detected) were captured using SAP Business Objects Business Intelligence software.

\section{Statistical analysis}

All analyses were performed using SAS V.9.4. The data are summarized in two ways: patient demographic characteristics based on the patient (table 1) and gap in care events characteristics based on the admission (table 2). All included patients had at least one gap in care detected in their EMR during the study period because the tool recognized only those meeting the criteria for gaps in care. The proportions of admissions with at least one gap in care event were compared between study periods using a binomial generalized estimating equations (GEE) model to account for the correlation between multiple admissions for the same patient, and ORs were used to quantify the magnitude and direction of the differences. The counts of gap in care events were compared between and within study periods, and between clinical services using this same GEE approach but with Poisson regression instead, 
HELP IMPROVE GLUCOSE CONTROL

Sliding scale insulin alone is inadequate to treat persistent hyperglycemia.

Better clinical outcomes can be achieved by treating patients with diabetes with scheduled insulin.

Insulin treatment recommendations:

Fasting hyperglycemia indicates need for basal insulin.

Hyperglycemia after meals indicates need for prandial insulin.

-If NPO: Combine basal plus correction (sliding scale).

-If PO: Combine basal and/or mealtime insulin plus correction (sliding scale).

-Update or obtain A1c as needed.

Basal insulins include detemir, glargine, degludec, and NPH. Mealtime insulins include aspart and lispro.

Basal insulin dosing to consider:

-Resume $75 \%$ of preadmission dose of basal insulin assessing risk for hypoglycemia.

OR

-Calculate total daily basal insulin to be 0.1 to 0.3 units $x \mathrm{~kg}$ per day. For example, if considering 0.2

units $\mathrm{x} \mathrm{kg}$, a $100 \mathrm{~kg}$ person may require 20 units of basal insulin per day.

Prandial insulin dosing to consider (if eating):

-Calculate total prandial insulin to be 0.1 to 0.3 units $x \mathrm{~kg}$ per day divided in 3 doses. For example, a $100 \mathrm{~kg}$ person may require 20 units of prandial insulin per day in addition to basal insulin. This is equivalent to 6 or 7 units of insulin with each meal.

Alerts may appear in the electronic records of patients with and without diabetes. The absence of alerts in other patients should NOT be interpreted as no action required for glucose management. This is a clinical tool in progress.

Figure 3 Example of alert notification and management recommendations for inappropriate insulin sliding scale as monotherapy in a patient with type 2 diabetes with recurrent hyperglycemia.

and incidence rate ratios (IRRs) were used to quantify the magnitude and direction of the differences. The logarithm of the length of stay was used as an offset for the Poisson regression since the length of stay for each admission varied from less than 1 day to over 86 days. The $p$ values in table 2 are adjusted for multiple comparisons using the false discovery rate method. ${ }^{33}$

\section{RESULTS}

The adult hospital population during this pilot project was represented by 52611 persons with or without diabetes admitted within 12 months to all medical and surgical services in inpatient, observation, and same-day admission units, and emergency department. There was a total of 15454 admissions (inpatient status) corresponding to patients with or without diabetes in whom decision support recommendations could have been evoked if criteria were met for dysglycemia or inappropriate insulin use. These included 4027 patients with type 2 diabetes, 334 with type 1 diabetes, and 11093 without diabetes. Table 1 presents a demographic summary represented by 3588 admitted subjects in whom gaps in care were recognized and alerts with recommendations evoked in their electronic medical records during the ON or OFF periods, but not crossing over periods. Most subjects were middle aged and had a similar distribution of gender with some male predominance. Race and ethnicity distribution is shown. Most gaps in care events were evoked among subjects admitted to non-intensive care and medical services.

There were 18564 gaps in care events evoked for abnormal glucose control and/or inappropriate insulin use among 3807 subjects during the entire pilot period. After exclusion of patients crossing over periods ( $\mathrm{ON}$ to OFF or OFF to ON) the final patient sample was 3588 ascribing to 4961 total admissions. We excluded 2531 gap in care events evoked in patients whose hospitalization crossed over study periods. Of the final 16033 gap in care events, fewer occurred during the ON period ( 7707 , mean $=3.12$ ) than during the OFF period (8326, mean $=3.35)$ although not statistically significant (IRR $=0.97,95 \%$ CI 0.92 to $1.03, \mathrm{p}=0.438$ ). Categorized by specific scenarios describing gaps in care, the following number of events and percentage of admissions with 
Table 1 Demographics and admission characteristics of study subjects

\begin{tabular}{ll}
\hline Variable & Total ${ }^{\star}(\mathbf{N}=\mathbf{3 5 8 8})$ \\
\hline $\begin{array}{l}\text { Age (years) } \\
\text { Unknown }\end{array}$ & $63.90 \pm 15.06$ \\
Gender & $90(2.5)$ \\
\hline Female & $1553(43.1)$ \\
\hline Male & $1970(54.4)$ \\
\hline Unknown & $90(2.5)$ \\
\hline Race & \\
\hline Asian & $54(1.5)$ \\
\hline African-American & $247(6.9)$ \\
\hline Caucasian & $2948(82.2)$ \\
\hline Other & $238(6.6)$ \\
\hline Unknown & $101(2.8)$ \\
\hline Hispanic & \\
\hline Yes & $207(5.7)$ \\
\hline No & $3271(91.2)$ \\
\hline Unknown & $112(3.1)$ \\
\hline Number of admissions & $1.38 \pm 0.93$ \\
\hline Patients with readmission & $786(21.9)$ \\
\hline Medical service of first alert & \\
\hline Surgical & $1191(33.2)$ \\
\hline Obstetrics/Gynecology & $40(1.1)$ \\
\hline Medical & $2356(65.7)$ \\
\hline Unknown & $1(0.0)$ \\
\hline ICU for first alert & $430(12.0)$ \\
\hline MeantSD $n(\%)$. & \\
\hline
\end{tabular}

${ }^{*}$ Mean \pm SD or $\mathrm{n}(\%)$.

ICU, intensive care unit.

at least one event were evoked during $\mathrm{ON}$ versus $\mathrm{OFF}$ periods respectively: (1) recurrent hyperglycemia in subjects with type 1 or 2 diabetes (3342 vs 3701, 64.2\% vs $66.9 \%, \mathrm{OR}=0.88,95 \%$ CI 0.79 to $0.98, \mathrm{p}=0.050$ ), (2) recurrent hyperglycemia in subjects with stress hyperglycemia (288 vs $506,7.5 \%$ vs $12.5 \%$, OR $=0.60,95 \%$ CI 0.51 to $0.72, \mathrm{p}<0.001)$, (3) hypoglycemia or impending hypoglycemia ( 1548 vs $1349,36.8 \%$ vs $33.2 \%, \mathrm{OR}=1.15$, $95 \%$ CI 1.02 to $1.29, \mathrm{p}=0.050$ ), (4) inappropriate insulin use as SSI monotherapy in subjects with type 1 diabetes ( 10 vs $22,0.2 \%$ vs $0.6 \%, \mathrm{OR}=0.36,95 \%$ CI 0.13 to 0.97 , $\mathrm{p}=0.073$ ), (5) inappropriate insulin use as SSI monotherapy in subjects with type 2 diabetes (2519 vs 2748 , $43.2 \%$ vs $44.0 \%, \mathrm{OR}=0.97,95 \%$ CI 0.87 to $1.08, \mathrm{p}=0.632$ ), and (6) inappropriate insulin use as SSI monotherapy in subjects with stress hyperglycemia (1617 vs $1488,28.1 \%$ vs $23.1 \%, \mathrm{OR}=1.30,95 \%$ CI 1.16 to $1.46, \mathrm{p}=<0.001)$ shown in table 2.

Greater count of hypoglycemia or impending hypoglycemia events when the tool was active may suggest that more proactive management of hyperglycemia could have resulted in an increased rate of hypoglycemia during the
ON period. To further evaluate this matter, we conducted a subsequent analysis to determine whether recommendations to treat elevated glucose or to avoid insulin sliding scales as monotherapy in patients with hyperglycemia could have directly predisposed to subsequent hypoglycemia and as a result evoked more gap in care events for hypoglycemia. We also analyzed whether having been identified with hypoglycemia or near hypoglycemia by the clinical decision support tool would result in fewer subsequent hypoglycemic events. We performed an analysis of the frequency and mean of hypoglycemia gap in care events in two different ways; (A) after an initial hypoglycemia alert to assess the contribution of the diabetes CDS tool in preventing subsequent hypoglycemia events and (B) after an initial non-hypoglycemia alert to determine whether it promoted subsequent hypoglycemia events. The mean of hypoglycemia events following a previous hypoglycemia alert was smaller in the $\mathrm{ON}(1.78)$ than in the OFF (1.87) but did not reach statistical significance (IRR $=1.09,95 \%$ CI 0.91 to $1.30, \mathrm{p}=0.438$ ) suggesting that alerting for hypoglycemia did not prevent subsequent hypoglycemic episodes. The mean of hypoglycemia events following a non-hypoglycemia alert was smaller in the ON (1.69) than in the OFF (1.70) period and not significantly different (IRR $=1.02,95 \%$ CI 0.86 to 1.21 , $\mathrm{p}=0.846$ ). This indicates that there was not an increase in hypoglycemic events after the CDS tool alerted for hyperglycemia or inappropriate insulin use. The values programed in the tool to alert for hypoglycemia or impending hypoglycemia were $\leq 3.9$ and $\leq 4.4 \mathrm{mmol} / \mathrm{L}$ ( $\leq 70$ and $\leq 80 \mathrm{mg} / \mathrm{dL}$ ), respectively. Records of glucose values representing all first hypoglycemic events during the pilot were $660(5.72 \%)$ corresponding to at risk or impending hypoglycemia values between $3.94 \mathrm{mmol} / \mathrm{L}$ and $4.4 \mathrm{mmol} / \mathrm{L}(71-80 \mathrm{mg} / \mathrm{dL}) ; 394(3.42 \%)$ to mild hypoglycemia with values between to $2.28 \mathrm{mmol} / \mathrm{L}$ and $3.9 \mathrm{mmol} / \mathrm{L}(41-70 \mathrm{mg} / \mathrm{dL})$; and $17(0.15 \%)$ denoting severe hypoglycemia with values $\leq 2.2 \mathrm{mmol} / \mathrm{L}$ ( $\leq 40 \mathrm{mg}$ / dL). Following initial events evoked, subsequent hypoglycemia events (recurrent hypoglycemia) accounted for $244(2.23 \%)$ values between $3.94 \mathrm{mmol} / \mathrm{L}$ and $4.4 \mathrm{mmol} / \mathrm{L} \quad(71-80 \mathrm{mg} / \mathrm{dL}) ; 202 \quad(1.84 \%)$ values between $2.28 \mathrm{mmol} / \mathrm{L}$ and $3.9 \mathrm{mmol} / \mathrm{L}(41-70 \mathrm{mg} / \mathrm{dL})$; and $13(0.12 \%)$ values $\leq 2.2 \mathrm{mmol} / \mathrm{L}(40 \mathrm{mg} / \mathrm{dL})$. This illustrates that the majority of events evoked for hypoglycemia either initial or recurrent corresponded to impending hypoglycemia, which is important although less concerning than established hypoglycemia.

We conducted a comparison between both ON and OFF periods. There was no significant difference between the number of events evoked for any of the gaps of care during the first and second OFF periods. Comparing the two ON periods, the first period showed a significantly greater number of events and percentage of hypoglycemia $(485,36.7 \%)$ compared with the second $(425,34.0 \%)(\mathrm{OR}=1.26,95 \%$ CI 1.06 to 1.49$), \mathrm{p}=0.007)$, as well as fewer number and percentage of events corresponding to stress hyperglycemia (54 vs 131, $4.4 \%$ vs 
Table 2 Gap in care events per admission

\begin{tabular}{|c|c|c|c|c|c|}
\hline Variable & $\begin{array}{l}\text { Alerts on } \\
\mathrm{n}=2472 \\
\text { admissions }\end{array}$ & $\begin{array}{l}\text { Alerts off } \\
n=2489 \\
\text { admissions }\end{array}$ & $\begin{array}{l}\text { OR } \\
\text { (on vs off) }\end{array}$ & $\begin{array}{l}\text { Unadjusted } \\
\text { p value }\end{array}$ & $\begin{array}{l}\text { Adjusted } \\
\text { p value }\end{array}$ \\
\hline \multicolumn{6}{|l|}{ All gap in care events } \\
\hline Total events across all admissions & 7707 & 8326 & & & \\
\hline Number of events per admission & $3.12 \pm 2.93$ & $3.35 \pm 3.24$ & 0.97 (0.92 to 1.03$)$ & 0.347 & 0.438 \\
\hline \multicolumn{6}{|c|}{ Events of hyperglycemia in subjects with diabetes } \\
\hline Total events across all admissions & 3342 & 3701 & & & \\
\hline Admissions with at least one event & $1586(64.2)$ & $1666(66.9)$ & 0.88 (0.79 to 0.98$)$ & 0.023 & 0.05 \\
\hline Number of events per admission & $1.35 \pm 1.65$ & $1.49 \pm 1.86$ & 0.94 (0.87 to 1.02$)$ & 0.12 & 0.179 \\
\hline \multicolumn{6}{|l|}{ Events of stress hyperglycemia } \\
\hline Total events across all admissions & 288 & 506 & & & \\
\hline Admissions with at least one event & $185(7.5)$ & $310(12.5)$ & 0.60 (0.51 to 0.72$)$ & $<0.001$ & $<0.001$ \\
\hline Number of events per admission & $0.12 \pm 0.58$ & $0.20 \pm 0.70$ & $0.59(0.46$ to 0.76$)$ & $<0.001$ & $<0.001$ \\
\hline \multicolumn{6}{|c|}{ Events of hypoglycemia or impending hypoglycemia } \\
\hline Total events across all admissions & 1548 & 1349 & & & \\
\hline Admissions with at least one event & $910(36.8)$ & $826(33.2)$ & 1.15 (1.02 to 1.29$)$ & 0.023 & 0.05 \\
\hline Number of events per admission & $0.63 \pm 1.08$ & $0.54 \pm 1.04$ & $1.22(1.07$ to 1.40$)$ & 0.003 & 0.010 \\
\hline \multicolumn{6}{|c|}{ Events of inappropriate insulin use as sliding scale monotherapy in patients with type 1 diabetes } \\
\hline Total events across all admissions & 10 & 22 & & & \\
\hline Admissions with at least one event & $6(0.2)$ & $16(0.6)$ & $0.36(0.13$ to 0.97$)$ & 0.044 & 0.073 \\
\hline Number of events per admission & $0.0 \pm 0.09$ & $0.01 \pm 0.12$ & $0.12(0.02$ to 0.63$)$ & 0.012 & 0.035 \\
\hline \multicolumn{6}{|c|}{ Events of inappropriate insulin use as sliding scale monotherapy in patients with type 2 diabetes } \\
\hline Total events across all admissions & 2519 & 2748 & & & \\
\hline Admissions with at least one alert & $1069(43.2)$ & $1096(44.0)$ & $0.97(0.87$ to 1.08$)$ & 0.59 & 0.632 \\
\hline Number of events per admission & $1.02 \pm 1.72$ & $1.10 \pm 1.88$ & $0.96(0.87$ to 1.05$)$ & 0.38 & 0.438 \\
\hline \multicolumn{6}{|c|}{ Events of Inappropriate insulin use as sliding scale monotherapy in patients with stress hyperglycemia } \\
\hline Total events across all admissions & 1617 & 1488 & & & \\
\hline Admissions with at least one event & $695(28.1)$ & $575(23.1)$ & $1.30(1.16$ to 1.46$)$ & $<0.001$ & $<0.001$ \\
\hline Number of events per admission & $0.65 \pm 1.47$ & $0.60 \pm 1.55$ & $1.16(1.02$ to 1.33$)$ & 0.027 & 0.05 \\
\hline \multicolumn{6}{|c|}{ Events of hypoglycemia events following the first non-hypoglycemia event } \\
\hline Total events across all admissions & 668 & 619 & & & \\
\hline Number of events per admission & $1.69 \pm 1.08$ & $1.70 \pm 1.19$ & $1.02(0.86$ to 1.21$)$ & 0.846 & 0.846 \\
\hline \multicolumn{6}{|c|}{ Events of hypoglycemia events following the first hypoglycemia event } \\
\hline Total events across all admissions & 638 & 523 & & & \\
\hline Number of events per admission & $1.78 \pm 1.23$ & $1.87 \pm 1.40$ & $1.09(0.911 .30)$ & 0.361 & 0.438 \\
\hline
\end{tabular}

$\mathrm{N}(\%)$; Effect size = Odds Ratio from binomial generalized estimating equations (GEE) model.

Mean \pm SD; Effect size=Incidence Rate Ratio from Poisson generalized estimating equations (GEE) model.

$\mathrm{IRR}$, incidence rate ratio.

$10.5 \%) \quad(\mathrm{OR}=0.44,95 \%$ CI 0.29 to $0.56, \mathrm{p}=<0.001)$. When analyzing admitting medical and surgical services independently, we found that the differences in gap in care events between $\mathrm{ON}$ and $\mathrm{OFF}$ periods were consistent with the differences observed in the entire cohort with few exceptions. The significance found for fewer events of hyperglycemia among patients with diabetes was observed in both disciplines combined but not when analysing these disciplines separately. There was no increase of hypoglycemic events in the surgical services.

To examine the behavior of the tool during the contiguous periods, we compared the findings between the first and the second $\mathrm{ON}$ and OFF periods, respectively. Both ON periods independently behaved similar to the two ON study periods together. The first ON period in comparison with the first OFF showed the same level of 
significance for all gaps in care event categories as the entire pilot cohort with the exception of the events representing inappropriate insulin use as SSI monotherapy in subjects with stress hyperglycemia. In this category, the number and percentage of events still remained larger in the ON period in contrast with the OFF period ( 348 vs $287,28.5 \%$ vs $24.6 \%$ ) ( $\mathrm{OR}=0.84,95 \%$ CI 0.71 to 1.00 , $\mathrm{p}=0.050$ ). The second $\mathrm{ON}$ and OFF periods showed statistical differences for all gaps in care event categories in alignment with those shown in the entire study cohort. This denoted consistency in the findings across periods.

\section{DISCUSSION}

The diabetes CDS program resulted in significant reduction of events of hyperglycemia among hospitalized patients with type 1 diabetes, type 2 diabetes and hyperglycemia. Fewer events were recognized for severe hyperglycemia $\geq 13.88 \mathrm{mmol} / \mathrm{L}(250 \mathrm{mg} / \mathrm{dL})$ or recurrent hyperglycemia $\geq 10.0 \mathrm{mmol} / \mathrm{L}(180 \mathrm{mg} / \mathrm{dL})$ among patients with type 1 or type 2 diabetes and stress hyperglycemia during the active period. The use of real-time CDS tool resulted in a $10 \%$ reduction of recurrent hyperglycemia in subjects with type 1 or 2 diabetes, $43 \%$ less recurrent hyperglycemia in subjects with stress hyperglycemia, $55 \%$ and $8 \%$ reduction in inappropriate insulin use in subjects with type 1 diabetes and type 2 diabetes respectively. The reduction in the number of gaps in care events suggests that the diabetes CDS tool assisted providers in making clinical decisions. Decision making in insulin management remained the judgement of clinicians as the tool was not designed to over-rule EMR activity or enter any automated orders or treatment changes. Improving glycemic control may improve outcome as it has been well established that dysglycemia and glycemic variability are detrimental ${ }^{34-36}$ and that adequate glycemic control reduces morbidity and mortality in intensive and nonintensive care settings. ${ }^{36} 37$

We observed fewer cases of inappropriate use of SSI as monotherapy during the active period observed among type 1 and type 2 diabetes patients with recurrent hyperglycemia. However, in type 1 diabetes this did not retain statistical significance in the adjusted analysis likely due to the small absolute numbers. The count of gap in care events for inappropriate use of SSI as monotherapy among patient with stress hyperglycemia was larger during the active period. This CDS tool aimed to convey a sense of urgency by alerting providers about the risk for DKA in patients with type 1 diabetes receiving SSI monotherapy. Similarly, it intended to heighten the interest in improving glycemic control among patients with stress hyperglycemia who were receiving only ISS. In trying to explain the higher number of innapropriate SSI in stress hyperglycemia patients, we speculate that the low response to the messages advocating avoidance of sliding scales as monotherapy among patients with stress hyperglycemia could be related to the tendency of providers to omit stress hyperglycemia and fear of hypoglycemia when scheduling insulin. ${ }^{38}{ }^{39}$ It is possible that our message promoting improvement of glucose control could have been less impactful than if it had actually stated outcome benefits from reducing stress hyperglycemia. However, it is not completely understood why the number of events corresponding the use insulin monotherapy in stress hyperglycemia was significantly larger during the $\mathrm{ON}$ period. A possible explanation is that by alerting about stress hyperglycemia provider opted to only prescribe correctional insulin in some cases thus increasing the number if events recognizing SSI monotherapy. Clinical guidelines strongly discourage the use of SSI monotherapy in the management of persistent hyperglycemia of any origin and recommend scheduled insulin either basal or basal/prandial as clinically applicable. ${ }^{2-4} \mathrm{~A}$ Cochrane study suggests that the evidence in favor of either SSI or basal-bolus therapy is equivocal. ${ }^{40}$ Sliding scale monotherapy was inferior to basal-bolus insulin in controlling glycemia and was associated with worse clinical outcomes among surgical patients with hyperglycemia. ${ }^{37}$ Using SSI alone is strongly discouraged for patients with type 2 diabetes or those with stress hyperglycemia given association with increased risk of hospital complications. ${ }^{37}$ Basal-bolus insulin therapy is the standard of care for patients with type 1 diabetes, and SSI monotherapy is contraindicated in patients with type 1 diabetes due to their absolute insulin dependency and risk for diabetic ketoacidosis.

In the design of this support tool, glucose values $3.9-4.4 \mathrm{mmol} / \mathrm{L} \quad(70-80 \mathrm{mg} / \mathrm{dL})$ were recognized as impending hypoglycemia and $\leq 3.9 \mathrm{mmol} / \mathrm{L}(70 \mathrm{mg} / \mathrm{dL})$ as established hypoglycemia. More than half the events for hypoglycemia that were evoked by the tool were for impending hypoglycemia. Nonetheless, it is especulated that intensification of management could have resulted in an increase of events evident by a larger number of gap in care scenarios evoked. For this, we conducted additional analyses that concluded the tool did not result in additional hypoglycemic events. The mean of hypoglycemia events following a previous hypoglycemia alert was smaller, while the tool was active in the EMR, which may suggest a trend for prevention of hypoglycemia after an alert is evoked. Recognizing stringent glucose control at higher glucose level than the current design will constitute a future optimization to the tool to provide additional support in preventing hypoglycemia.

Commercially available FDA-approved computerized software have been used in hospitalized patients to assess efficacy and safety of intravenous insulin administration, including DKA management. Some have expanded to programs for subcutaneous insulin therapy. These programs are automated insulin titration regimens according to prescribed glycemic targets. ${ }^{41-43}$ In contrast, our CDS tool capitalizes on detecting and alerting clinicians about gaps in care, presenting corresponding aggregated glucose data, and conveying evidence-based recommendations for management considerations. Our tool demonstrated its efficacy using bedside point-of-care 
glucose values. Given the advances in interoperable HIT infrastructures and interfacing programming, and as continuous glucose monitoring systems (CGMS) validation continues making progress, the concept of CGMS data integrated with diabetes CDS seems a feasible and exciting innovation. Additional research using these integrated technologies could lead to discovering how CGMS and CDS programs may synergistically enhance recognition of glycemic patterns and assist with more personalized management of dysglycemia, thus further optimizing patient care.

Our findings indicating no difference in the number of gaps in care events during the ON period between medical and surgical services suggest that providers from different disciplines respond similarly to the tool. This evidence presents an incentive to move forward with initiatives integrating CDS that can be adopted by a wide range of clinicians across inpatient services. The adult endocrinology service in our institution is primarily a consultative service that responds to requests for inpatient management of diabetes from different disciplines. This CDS tool was not under the supervision of endocrinology and did not have a noticeable bearing on its practice or number of consults attributed to the service. However, we consider a limitation not having tangible evidence about the program's impact on the number of endocrine consults during the $\mathrm{ON}$ and OFF periods of the study. Our analysis did not include the proportions of providers who may have received single or multiple message corresponding to the same or different gaps in care evoked by the tool. This limited our ability to determine how single or repeated exposure to these gaps and to the corresponding standard of care notifications could have impacted clinicians' knowledge and practice performance. Even though we captured diagnoses as discrete data elements in the EMR, a potential shortcoming of the study is that we may have failed to recognize gap in care events among patients with type 1 and type 2 diabetes who did not have diagnosis listed in their EMR. In that context, if hyperglycemia was recognized, events were categorized as stress hyperglycemia by the tool until a diagnosis was documented and became a common data element.

\section{CONCLUSIONS}

This work presents the development and pilot of a real-time glucose management CDS tool to recognize scenarios departing from best practices in the hospital. We capitalized on a design that recognizes gaps in hospital diabetes care based on scientific evidence for diagnosis and management, that circumvents barriers jeopardizing adequate glycemic control, and that reduces the burden of data gathering and processing. Our program focuses on resolving inpatient dysglycemia, and it pioneers a program that advances the vision of learning health systems using a hospital-wide CDS system. This work proves advancements in a clinical application of Health
Information Technology to enable quality improvement within a clinical field of major significance. This approach aligns with goals of learning health systems as it contributes in closing clinically relevant gaps in care while understanding effects of the tool through its implementation and in the context of practice. ${ }^{19} 203144$

We propose that this CDS tool using a case-finding approach and real-time electronic notifications has promising attributes to improve glycemic care in the hospital. It enables an innovative form of clinical communication that can be implemented to lessen the existing mismatch between the demand and supply of diabetes expertise in hospitals. It demonstrates positive influence on practice performance without invading or superseding clinical judgement and decision making. It is applicable to various hospital settings and clinical disciplines. Our program will subsequently assess the impact of the tool on important clinical and economic endpoints relevant to diabetes and glycemic management. Further steps are needed to provide information about the tool's ability in lessening the burden of searching and analyzing disperse glucose data for decision making and on providers perspectives and performance.

Future research focusing of the benefits of this CDS integrated with other modalities of CDS or with continuous glucose monitoring systems is encouraging. This approach can enable designs correlating glycemic patterns recognition and predictive analysis thus providing a greater opportunity to individualize to care. This actionable program supporting glycemic management in the hospital can accelerate resolving a protracted multifactorial problem that impacts the lives of millions of people on a daily basis.

\section{Author affiliations}

${ }^{1}$ Department of Medicine, Penn State Health Milton S Hershey Medical Center, Hershey, Pennsylvania, USA

${ }^{2}$ Department of Medicine, Emory University, Atlanta, Georgia, USA

${ }^{3}$ Department of Public Health Sciences, Penn State College of Medicine, Hershey,

Pennsylvania, USA

${ }^{4}$ Department of Information Services, Penn State Health Milton S Hershey Medical Center, Hershey, Pennsylvania, USA

${ }^{5}$ Department of Emergency Medicine, Penn State Health Milton S Hershey Medical Center, Hershey, Pennsylvania, USA

${ }^{6}$ Department of Medicine, Public Health Sciences, and Humanities, Penn State Health Milton S Hershey Medical Center, Hershey, Pennsylvania, USA

Acknowledgements The authors would like to thank Dr Colleen Rafferty, Valerie Mouery, Ann Gartner, Corinna Haggerty, Michael Ward, and Andrew Pavone for their important contribution in the development of this diabetes clinical decision support tool (CDS), and Dr Andrea Manni for his feedback on this manuscript.

Contributors AP-L is the study's $\mathrm{Pl}$ and author of the original idea who contributed to the design and implementation of the CDS tool, study conduct and integrity, data collection, analysis, and interpretation, and manuscript writing. GU contributed with expertise on the content of the CDS tool, interpretation of findings, and manuscript editorial. EBL contributed to the data management, analysis, and interpretation, and manuscript preparation. MDB contributed to the data collection, data integrity and interpretation, and manuscript editorial. CJD contributed to the design and implementation of the CDS tool, and manuscript editorial. VMC contributed in the statistical design, data analysis and manuscript editorial. PMH contributed to the design of the CDS tool, study integrity, interpretation of findings, and manuscript preparation. AP-L is the guarantor of this manuscript. 
Funding AP-L is supported by a career development award from the National Institute of Diabetes Digestive and Kidney Disease K23DK107914-05 and by The Eberly Medical Research Innovation Fund, which permitted the conduct of this work.

Competing interests None declared.

Patient consent for publication Not required.

Ethics approval This study was approved by The Penn State Health and Penn State College of Medicine Institutional Review Board (IRB) as STUDY00003330. The IRB waived the requirement of written informed consent.

Provenance and peer review Not commissioned; externally peer reviewed.

Data availability statement All data relevant to the study are included in the article. Deidentified subject data.

Open access This is an open access article distributed in accordance with the Creative Commons Attribution Non Commercial (CC BY-NC 4.0) license, which permits others to distribute, remix, adapt, build upon this work non-commercially, and license their derivative works on different terms, provided the original work is properly cited, appropriate credit is given, any changes made indicated, and the use is non-commercial. See: http://creativecommons.org/licenses/by-nc/4.0/.

\section{ORCID iDs}

Ariana Pichardo-Lowden http://orcid.org/0000-0003-4504-4376

Guillermo Umpierrez http://orcid.org/0000-0002-3252-5026

\section{REFERENCES}

1 Institute of Medicine (US). Roundtable on Value \& Science-Driven Health Care. In: Yong PL OL, McGinnis JM, eds. Value in health care: accounting for cost, quality, safety, outcomes, and innovation. Washington (DC): National Academies Press (US), 2010.

2 Association AD. 15. diabetes care in the hospital. Diabetes Care 2020;43:S193-202.

3 Moghissi ES, Korytkowski MT, DiNardo M, et al. American association of clinical endocrinologists and American diabetes association consensus statement on inpatient glycemic control. Diabetes Care 2009;32:1119-31.

4 Umpierrez GE, Hellman R, Korytkowski MT, et al. Management of hyperglycemia in hospitalized patients in non-critical care setting: an endocrine Society clinical practice guideline. J Clin Endocrinol Metab 2012;97:16-38.

5 Pichardo-Lowden AR, Haidet PM. Closing the loop: optimizing diabetes care in the hospital by addressing dispersed information in electronic health records and using clinical decision support. $J$ Diabetes Sci Technol 2019;13:783-9.

6 Pichardo-Lowden AR, Kong L, Haidet PM. Knowledge, attitudes, and decision making in hospital glycemic management: are faculty up to speed? Endocr Pract 2015;21:307-22.

7 Ladeira RT, Simioni ACM, Bafi AT, et al. Diabetes mellitus and impaired glucose tolerance are underdiagnosed in intensive care units. Rev Bras Ter Intensiva 2012;24:347-51.

8 Levetan CS, Passaro M, Jablonski K, et al. Unrecognized diabetes among hospitalized patients. Diabetes Care 1998;21:246-9.

9 Cheekati V, Osburne RC, Jameson KA, et al. Perceptions of resident physicians about management of inpatient hyperglycemia in an urban Hospital. J Hosp Med 2009;4:E1-8.

10 Giangola J, Olohan K, Longo J, et al. Barriers to hyperglycemia control in hospitalized patients: a descriptive epidemiologic study. Endocr Pract 2008;14:813-9.

11 Allende-Vigo MZ, González-Rosario RA, González L, et al. Inpatient management of diabetes mellitus among Noncritically ill patients at university hospital of Puerto Rico. Endocr Pract 2014;20:452-60.

12 Cook CB, Jameson KA, Hartsell ZC, et al. Beliefs about Hospital diabetes and perceived barriers to glucose management among inpatient midlevel practitioners. Diabetes Educ 2008;34:75-83.

13 Coan KE, Schlinkert AB, Beck BR, et al. Clinical inertia during postoperative management of diabetes mellitus: relationship between hyperglycemia and insulin therapy intensification. $J$ Diabetes Sci Technol 2013;7:880-7.

14 Cook CB, Castro JC, Schmidt RE, et al. Diabetes care in hospitalized noncritically ill patients: more evidence for clinical inertia and negative therapeutic momentum. J Hosp Med 2007;2:203-11.

15 Griffith ML, Boord JB, Eden SK, et al. Clinical inertia of discharge planning among patients with poorly controlled diabetes mellitus. $J$ Clin Endocrinol Metab 2012;97:2019-26.

16 Cook CB, McNaughton DA, Braddy CM, et al. Management of inpatient hyperglycemia: assessing perceptions and barriers to care among resident physicians. Endocr Pract 2007;13:117-24.
17 Horton WB, Law S, Darji M, et al. Construction and preliminary evaluation of the inpatient glycemic control questionnaire (IGCQ) a survey tool assessing perceptions and knowledge of resident physicians. BMC Med Educ 2019;19:228.

18 Pichardo-Lowden A, Haidet P, Umpierrez GE. Perspectives on learning and clinical practice improvement for diabetes in the hospital: a review of educational interventions for providers. Endocr Pract 2017;23:614-26.

19 HealthIT.gov. Clinical decision support. secondary clinical decision support, 2018. Available: https://www.healthit.gov/topic/safety/ clinical-decision-support

20 Tcheng JE, Bakken S, Bates DW, et al. Optimizing strategies for clinical decision support: summary of a meeting series. Washington DC: National Academy of Medicine, 2017.

21 Jia P, Zhao P, Chen J, et al. Evaluation of clinical decision support systems for diabetes care: an overview of current evidence. J Eval Clin Pract 2019;25:66-77.

22 Jeffery R, Iserman E, Haynes RB, et al. Can computerized clinical decision support systems improve diabetes management? A systematic review and meta-analysis. Diabet Med 2013;30:739-45.

23 Nirantharakumar K, Chen YF, Marshall T, et al. Clinical decision support systems in the care of inpatients with diabetes in non-critical care setting: systematic review. Diabet Med 2012;29:698-708.

24 Varghese J, Kleine M, Gessner SI, et al. Effects of computerized decision support system implementations on patient outcomes in inpatient care: a systematic review. J Am Med Inform Assoc 2018;25:593-602.

25 Montero AR, Dubin JS, Sack P, et al. Future technology-enabled care for diabetes and hyperglycemia in the hospital setting, 2019. Available: http://wwwwjgnetcom/

26 Thabit H, Hovorka R. Bridging technology and clinical practice: innovating inpatient hyperglycaemia management in non-critical care settings. Diabet Med 2018;35:460-71.

27 Mathioudakis N, Jeun R, Godwin G, et al. Development and implementation of a subcutaneous insulin clinical decision support tool for hospitalized patients. J Diabetes Sci Technol 2019;13:522-32.

28 Aberer F, Lichtenegger KM, Smajic E, et al. GlucoTab-guided insulin therapy using insulin Glargine U300 enables glycaemic control with low risk of hypoglycaemia in hospitalized patients with type 2 diabetes. Diabetes Obes Metab 2019;21:584-91.

29 Rushakoff RJ, Sullivan MM, MacMaster HW, et al. Association between a virtual glucose management service and glycemic control in hospitalized adult patients: an observational study. Ann Intern Med 2017;166:621-7.

30 Sheen Y-J, Huang C-C, Huang S-C, et al. Implementation of an electronic DASHBOARD with a remote management system to improve glycemic management among hospitalized adults. Endocr Pract 2020;26:179-91.

31 The Office of the National Coordinator for Health Information Technology. Health it enabled quality improvement: a vision for better health and health care. Washington, DC, 2014.

32 Pichardo-Lowden AR, Prokop A, Paul H. Perspectives of healthcare providers on diabetes care in the hospital: a qualitative needs assessment study. unpublished manuscript. Penn State University, 2020.

33 Benjamini Y, Hochberg Y. Controlling the false discovery rate: a practical and powerful approach to multiple testing. Journal of the Royal statistical society: series B 1995;57:289-300.

34 van den Berghe $G$, Wouters $P$, Weekers $F$, et al. Intensive insulin therapy in critically ill patients. N Engl J Med 2001;345:1359-67.

35 NICE-SUGAR Study Investigators, Finfer S, Chittock DR, et al. Intensive versus conventional glucose control in critically ill patients. N Engl J Med 2009;360:1283-97.

36 Krinsley JS, Maurer P, Holewinski S, et al. Glucose control, diabetes status, and mortality in critically ill patients: the continuum from intensive care unit admission to hospital discharge. Mayo Clin Proc 2017;92:1019-29.

37 Umpierrez GE, Smiley D, Jacobs S, et al. Randomized study of basal-bolus insulin therapy in the inpatient management of patients with type 2 diabetes undergoing general surgery (rabbit 2 surgery). Diabetes Care 2011;34:256-61.

38 Malcolm JC, Kocourek J, Keely E, et al. Implementation of a screening program to detect previously undiagnosed dysglycemia in hospitalized patients. Can J Diabetes 2014;38:79-84.

39 Montori VM, Bistrian BR, McMahon MM. Hyperglycemia in acutely ill patients. JAMA 2002;288:2167-9.

40 Colunga-Lozano LE, Gonzalez Torres FJ, Delgado-Figueroa N, et al. Sliding scale insulin for non-critically ill hospitalised adults with diabetes mellitus. Cochrane Database Syst Rev 2018;11:CD011296. 
41 Glytec. eGlycemic management system. secondary eGlycemic management system, 2020. Available: https:// glytecsystems.com/solutions-overview/solutions-eglycemicmanagement-system/

42 Network MD. Glucostabilizer. Secondary Glucostabilizer, 2020. Available: http://glucostabilizer.net/
43 Technologies MM. EndoTool glucose management. secondary EndoTool glucose management, 2020. Available: https:// monarchmedtech.com/endotool-glucose-management/

44 Jones SS, Rudin RS, Perry T, et al. Health information technology: an updated systematic review with a focus on meaningful use. Ann Intern Med 2014;160:48-54. 